\title{
Playing with isostructurality: from tectons to molecular alloys and crystals of crystals
}

\author{
Pierre Dechambenoit, Sylvie Ferlay*, Nathalie Kyritsakas and Mir Wais Hosseini* \\ Received (in XXX, XXX) Xth $X X X X X X X X X 200 X$, Accepted Xth XXXXXXXXX 200X \\ ${ }_{5}$ First published on the web Xth $X X X X X X X X X 200 X$ \\ DOI: 10.1039/b000000x
}

\begin{abstract}
The combination of isomorphous and isometric porous crystals based on charge-assisted $\mathrm{H}$ bonding leads to molecular alloys and composite crystals.
\end{abstract}

${ }_{10}$ For the "bottom up" strategy, i.e. the generation of materials from molecular components, the understanding and tuning of properties (chemical or physical) requires the control of selfassembly processes. Following the statement by Dunitz " $A$ crystal is, in a sense, the supramolecule par excellence", ${ }^{1}$ an

15 approach called molecular tectonics ${ }^{2}$ combining molecular recognition events ${ }^{3}$ with self-assembly processes, was developed over the last $c a$ two decades. For this approach, molecular crystals are seen as infinite periodic architectures ${ }^{4}$ resulting from the interconnection of building blocks or 20 tectons. $^{2}$ Thus, this strategy is mainly concerned with the design of connectivity patterns and their translation in space leading to the formation of molecular networks in the crystalline phase. ${ }^{5}$

Here, using a series of isostructural crystals, we describe the 25 formation of porous molecular alloys and composite crystals generated by 3-D epitaxial growth as well as the control of their ability to release water molecules.

A crystalline solid solution is a mixture of at least two crystalline solids that coexist as a new crystalline solid. When 30 the components of the solid solution are molecular entities, these systems are called molecular alloys. ${ }^{6}$ The majority of reported molecular solid solutions are inorganic in nature. However, few examples of organic ${ }^{7}$ or hybrid materials ${ }^{6 a, b}$ have been also reported.

${ }_{35}$ For the formation of crystals based on molecular networks, the combination of reversible $\mathrm{H}$-bonding ${ }^{8}$ with electrostatic interactions (charge-assisted H-bonding) ${ }^{9,10}$ is an interesting strategy. The latter, largely explored in the past ${ }^{9,10,11,12}$ is further developed in this contribution.

${ }_{40}$ We have shown that bis-amidinium dications, when associated with anionic partners, are suitable tectons for the generation of charge-assisted H-bonded infinite architectures. ${ }^{10}$ In particular, $\mathbf{1}-2 \mathrm{H}^{+}$and $\mathbf{2}-2 \mathrm{H}^{+}$(Fig. 1) are well designed to be combined with cyanometallate complex anions. ${ }^{13}$ The location

45 and orientation of the acidic protons are almost perfect for the recognition of both tetracyanometallates such as $\left[\mathrm{X}(\mathrm{CN})_{4}\right]^{2-}$ $(\mathrm{X}=\mathrm{Ni}, \mathrm{Pd}, \mathrm{Pt})^{13 \mathrm{~b}, \mathrm{f}}$ and $\left[\mathrm{X}(\mathrm{CN})_{6}\right]^{3-}(\mathrm{X}=\mathrm{Co}, \mathrm{Fe}, \mathrm{Cr}) .{ }^{13 \mathrm{a}, \mathrm{b}, \mathrm{e}}$ Indeed, in both cases, the recognition pattern is composed of two H-bonds in a dihapto mode (slightly bent $\mathrm{NH}---\mathrm{N}$ angle)

${ }_{50}$ between the acidic $\mathrm{H}$ atoms on each side of the cationic tecton and the $\mathrm{N}$ atoms of the complex anion (Fig. 1). 1-2 $\mathrm{H}^{+}$and 2$2 \mathrm{H}^{+}$are analogous and only differ by the peripheral substitution of two $\mathrm{H}$ atoms in $\mathbf{1}-2 \mathrm{H}^{+}$by $\mathrm{OH}$ groups in $\mathbf{2}-2 \mathrm{H}^{+}$. For the sake of simplification, we shall use the following 55 correspondence to design the cationic and anionic units: 1$2 \mathrm{H}^{+}=\mathrm{A}, 2-2 \mathrm{H}^{+}=\mathrm{B},\left[\mathrm{Cr}(\mathrm{CN})_{6}\right]^{3-}=\mathrm{X},\left[\mathrm{Fe}(\mathrm{CN})_{6}\right]^{3-}=\mathrm{Y}$ and $\left[\mathrm{Co}(\mathrm{CN})_{6}\right]^{3-}=\mathrm{Z}$ (Fig. 1). Interestingly, the combination of both $\mathrm{A}$ and $\mathrm{B}$ with $\mathrm{X}, \mathrm{Y}$ and $\mathrm{Z}$ leads to the formation of similar neutral 2-D networks offering hexagonal-type 60 channels occupied by water molecules ( 7 for A and 8 for B). The stoechiometry for all combinations is 3 dications for 2 trianions. Except for crystals of $\left(\mathrm{A}_{3} \mathrm{Y}_{2}\right)$ and $\left(\mathrm{A}_{3} \mathrm{Z}_{2}\right)$ which belong to the lower symmetry space group $P-1$, the other four combinations $\left(\mathrm{A}_{3} \mathrm{X}_{2}\right),\left(\mathrm{B}_{3} \mathrm{X}_{2}\right),\left(\mathrm{B}_{3} \mathrm{Y}_{2}\right)$ and $\left(\mathrm{B}_{3} \mathrm{Z}_{2}\right)$, belong to ${ }_{65}$ the $P 2{ }_{1} / n$ space group. ${ }^{14}$ It is interesting to note that the latter four crystals are isostructural (monoclinic, $P 2_{1} / n$, see crystallographic tables in ESI TS1). Owing to their rather close unit cell metrics (slight variation of $c a 1-4 \%$ on $a, b$ and $c$ parameters), they were considered as a small library of 70 interest for the generation of molecular alloys.

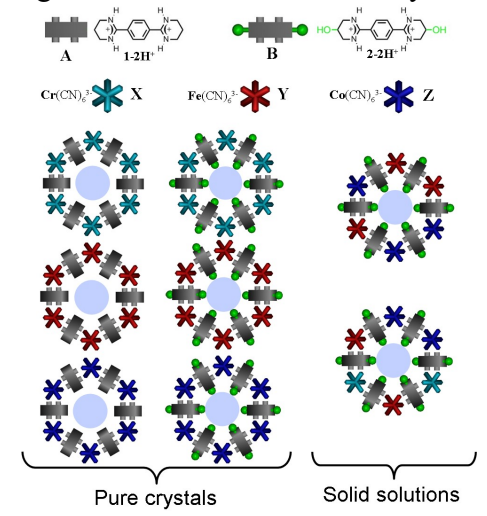

Figure 1: Schematic representations of portions of neutral 2-D H-bonded networks (pure crystals and solid solutions) formed between dicationic tectons $1-2 \mathrm{H}^{+}(\mathrm{A})$ and $2-2 \mathrm{H}^{+}(\mathrm{B})$ with and $\left[\mathrm{M}(\mathrm{CN})_{6}\right]^{3-}(\mathrm{M}=\mathrm{Cr}(\mathrm{X}$, light 75 blue), $\mathrm{Fe}$ (Y, red) or Co ( $\mathrm{Z}$, dark blue) complex anions. The blue circle represents 7 and 8 water molecules for $\mathrm{A}$ and $\mathrm{B}$ respectively.

Thus, both binary $\left(\mathrm{B}_{3} \mathrm{YZ}\right)$ and $\left(\mathrm{B}_{3} \mathrm{XY}\right)$ and ternary $\left(\mathrm{B}_{3} \mathrm{X}_{0.66} \mathrm{Y}_{0.66} \mathrm{Z}_{0.66}\right)$ alloys have been prepared by combining $\mathrm{B}$ with $\mathrm{X}, \mathrm{Y}$ and $\mathrm{Z}$. Both types of alloys were characterized by ${ }_{80}$ XRD studies (unit cell parameters determination, see ESI TS2). In the case of binary alloys, as expected from the Vegard's law, ${ }^{15}$ the cell parameters are between those of the pure crystals. Furthermore, since for $\mathrm{X}, \mathrm{Y}$ and $\mathrm{Z}$ anions the vibration frequencies of the cyanide group are different, IR 85 spectroscopy was used to demonstrate their simultaneous presence. Indeed, the $\mathrm{CN}$ vibration band for $\mathrm{X}\left(\mathrm{v}=2135 \mathrm{~cm}^{-}\right.$ $\left.{ }^{1}\right), \mathrm{Y}\left(v=2125 \mathrm{~cm}^{-1}\right)$ and $\mathrm{Z}\left(v=2143,2129 \mathrm{~cm}^{-1}\right)$ for their 
potassium salt, are shifted to lower frequency when potassium cation is replaced by $\mathrm{B}\left(\mathrm{v}=2129 \mathrm{~cm}^{-1}\right.$ for $\mathrm{B}_{3} \mathrm{X}_{2}, v=2115 \mathrm{~cm}^{-}$ ${ }^{1}$ for $B_{3} Y_{2}$ and $v=2137$ and $2126 \mathrm{~cm}^{-1}$ for $\left.B_{3} Z_{2}\right)$. Thus for the binary $\left(\left(\mathrm{B}_{3} \mathrm{YZ}\right)\right.$ and $\left.\left(\mathrm{B}_{3} \mathrm{XY}\right)\right)$ and ternary $\left(\mathrm{B}_{3} \mathrm{X}_{0.66} \mathrm{Y}_{0.66} \mathrm{Z}_{0.66}\right)$ 5 alloys, the bands corresponding to each species are observed separately (see ESI Fig. S1).

Among the three isostructural crystals obtained with $\mathrm{B}$, as expected only $\left(\mathrm{B}_{3} \mathrm{X}_{2}\right)$ is colored (yellow). This allowed us to demonstrate the possibility of tuning both the composition and 10 the color of the ternary alloy by varying the proportion of the different anionic components X, Y and Z (Fig. 2). Examples of binary molecular alloys have been reported. ${ }^{6,7}$

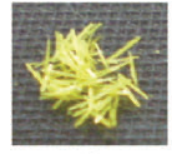

a

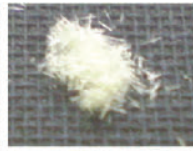

b

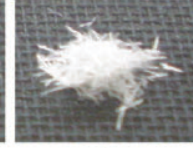

$c$

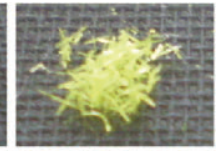

d
15 Figure 2. Pictures of pure crystals of $\mathrm{B}_{3} \mathrm{Y}_{2}(\mathrm{a}), \mathrm{B}_{3} \mathrm{X}_{2}(\mathrm{~b}), \mathrm{B}_{3} \mathrm{Z}_{2}(\mathrm{c})$, and the ternary crystalline alloy $\mathrm{B}_{3} \mathrm{X}_{0.66} \mathrm{Y}_{0.66} \mathrm{Z}_{0.66}(\mathrm{~d})$.

We have demonstrated above that both binary and ternary molecular alloys may be formed by combining the same dicationic tecton $\mathrm{B}$ with $\mathrm{X}, \mathrm{Y}$ and $\mathrm{Z}$ anions. The reverse, i.e. 20 the combination of the two organic tectons A and B with the same anion $\mathrm{X}$, is another possibility. Owing to the difference between $\mathrm{A}$ and $\mathrm{B}$, this case is particularly interesting since by imposing the $\mathrm{A} / \mathrm{B}$ ratio it should be possible to control the uptake and release of water molecules located in the channels. 25 Indeed, as demonstrated previously ${ }^{14}$ whereas for $A$, the interior of the channels are decorated with $\mathrm{H}$ atoms, for $\mathrm{B}$ the $\mathrm{OH}$ groups point towards the center and thus offer the possibility of stabilizing the water molecules by H-bonding (Fig. 1). Consequently, the dehydration temperature for 30 hydrated $\left(\mathrm{B}_{3} \mathrm{X}_{2}\right)$ was higher by $c a 40{ }^{\circ} \mathrm{C}$ when compared to hydrated $\left(\mathrm{A}_{3} \mathrm{X}_{2}\right)$. The fine-tuning of the temperature of water release was demonstrated by TGA measurements on a series of molecular alloys composed of X, A and B by imposing the $\mathrm{A} / \mathrm{B}$ ratio in the range of $0-1$ (Fig. 3).

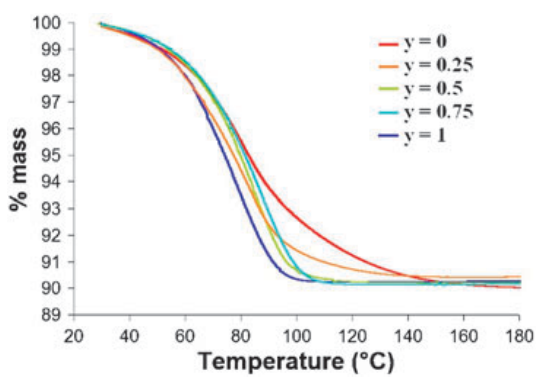

Figure 3: TGA curves of molecular alloys $\left(\mathrm{A}_{3 \mathrm{y}} \mathrm{B}_{3(1-\mathrm{y})} \mathrm{X}_{2}\right)$ formed by combining $\mathrm{X}$ with $\mathrm{A}$ and $\mathrm{B}$ in different proportions showing the finetuning of water release temperature.

As expected because of the hydrophilic nature of the channels 40 generated with $\mathrm{B}$, for the alloys, the water release temperature increases when the $\mathrm{B} / \mathrm{A}$ ratio is enhanced. However, the process is not linear. Indeed, the TGA study (Fig. 3) revealed almost the same thermal behavior for $\mathrm{y}=0.50$ and 0.75 (release of all water molecules at $c a 110^{\circ} \mathrm{C}$ ), for $\mathrm{y}=0$ and
${ }_{45} 0.25$, the release temperatures were found to be $\mathrm{c} a 140^{\circ} \mathrm{C}$ and ca $135^{\circ} \mathrm{C}$ respectively. This might suggest that $\mathrm{A}$ and $\mathrm{B}$ are not randomly distributed in the alloy. However, we were not able to further study this behavior.

It is worth noting that for solid solutions, periodicity applies 50 to occupation sites and not to the components since these are statistically distributed over the crystalline material. In order to achieve a hierarchical construction of crystalline materials, the formation of "crystals of crystals" (or composite crystals) was investigated. The formation of crystals of crystals may be 55 achieved by 3-D epitaxial growth of crystalline layers on a seed crystal. Only rare examples of molecular composite crystals have been reported by MacDonald-Palmore, ${ }^{16 a}$ StangMiller $^{16 \mathrm{~b}}$ and by us. ${ }^{6 \mathrm{~b}}$ Owing to their transparency and different refractive index of different crystalline layers, such ${ }_{60}$ composite crystals might offer some applications in optics. ${ }^{17}$

Based on the isostructurality (Fig. 1) and close metrics of crystals formed upon combining A with Y and Z (ESI TS1), we have previously reported the formation of composite crystals of the type $\left(A_{3} Y_{2}-A_{3} Z_{2}\right)$ or the reverse $\left(A_{3} Z_{2}-A_{3} Y_{2}\right){ }^{6 b}$

${ }_{65} \mathrm{We}$ have also demonstrated the viability of this technique by generating composite crystals using tecton $\mathrm{A}$ and $\left[\mathrm{X}(\mathrm{CN})_{6}\right]^{4-}$ $(\mathrm{X}=\mathrm{Fe}, \mathrm{Ru})$ anions. ${ }^{18}$

In order to visually demonstrate the formation of composite crystals, we have used as seed crystal the combination of 70 tecton B with Y (yellow crystals). For the growth of crystalline layers on the seed crystal, $\mathrm{B}$ was combined with $\mathrm{Z}$ affording $\left(\mathrm{B}_{3} \mathrm{Y}_{2}-\mathrm{B}_{3} \mathrm{Z}_{2}\right)$ (Fig. 4). The reverse, i.e. the formation of $\left(\mathrm{B}_{3} \mathrm{Z}_{2}-\mathrm{B}_{3} \mathrm{Y}_{2}\right)$ was also demonstrated (for experimental procedure see ESI Experimental part). In all cases, the 75 composite crystals have been studied by XRD in order to check the conservation of the crystallographic axes and the match of the cell parameters with those of the pure crystals.

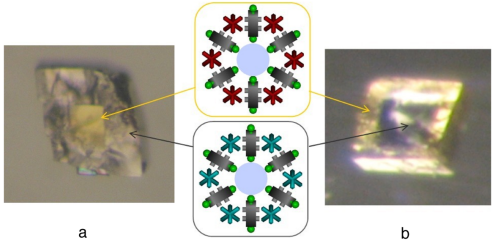

Figure 4: Slices of composite crystals obtained by epitaxial growth of 80 $\left(\mathrm{B}_{3} \mathrm{Z}_{2}\right)$ on $\left(\mathrm{B}_{3} \mathrm{Y}_{2}\right)(\mathrm{a})$ and $\left(\mathrm{B}_{3} \mathrm{Y}_{2}\right)$ on $\left(\mathrm{B}_{3} \mathrm{Z}_{2}\right)(\mathrm{b})$.

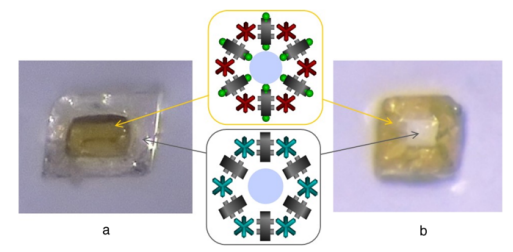

Figure 5: Slices of composite crystals obtained by epitaxial growth of $\left(\mathrm{A}_{3} \mathrm{X}_{2}\right)$ on $\left(\mathrm{B}_{3} \mathrm{Y}_{2}\right)(\mathrm{a})$ and $\left(\mathrm{B}_{3} \mathrm{Y}_{2}\right)$ on $\left(\mathrm{A}_{3} \mathrm{X}_{2}\right)(\mathrm{b})$.

More interestingly, whereas in the latter case we used the ${ }_{85}$ same tecton $\mathrm{B}$ and varied the anion ( $\mathrm{Y}$ or $\mathrm{Z}$ ), we were also able to change all four components. To the best of our knowledge this combination is unique. Indeed, we have combined tectons $\mathrm{A}$ and $\mathrm{B}$ with anions $\mathrm{X}$ and $\mathrm{Y}$. In other terms, starting with $\left(\mathrm{B}_{3} \mathrm{Y}_{2}\right)$, we generated the composite 90 crystal $\left(B_{3} Y_{2}-A_{3} X_{2}\right)$ (Fig. 5). Again, the formation of the reverse architecture $\left(A_{3} X_{2}-B_{3} Y_{2}\right)$ was also shown (Fig. 5). 
It is worth noting that whereas for molecular alloys described above, because of the random distribution of the molecular components in the crystal, no hierarchical property may be expected, in the present case, because of the stepwise 5 construction methodology, both crystalline phases should express their own specificity. Indeed, A and B differ by the presence of two $\mathrm{OH}$ groups and consequently, as stated above, crystals based on A and on B show different propensity to retain water molecules in their channels. Thus, for the 10 composite crystals, the temperature of water release is expected to be different for each crystalline layer.

Finally, we were also able to grow crystalline solids on molecular alloys. Indeed, starting from the binary alloy $\left(\mathrm{B}_{3} \mathrm{YZ}\right)$ or $\left(\mathrm{B}_{3} \mathrm{XY}\right)$, crystalline layer of $\left(\mathrm{A}_{3} \mathrm{X}_{2}\right)$ were generated 15 leading to crystals of crystals of the type $\left(\mathrm{B}_{3} \mathrm{YZ}-\mathrm{A}_{3} \mathrm{X}_{2}\right)$ and $\left(\mathrm{B}_{3} \mathrm{XY}-\mathrm{A}_{3} \mathrm{X}_{2}\right)$ (Fig. 6). It is worth noting that the two composite crystals reported here contain four (Fig. 6a) and five (Fig. 6b) different components with some of them distributed randomly (seed crystals), and others hierarchically 20 by epitaxial growth.

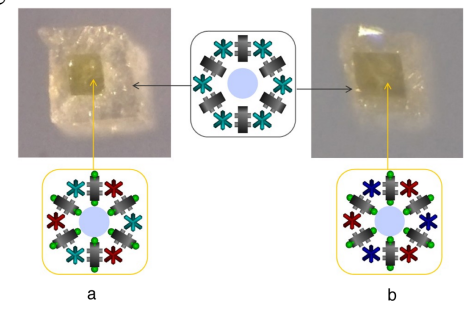

Figure 6: Slices of composite crystals obtained by epitaxial growth of $\left(\mathrm{B}_{3} \mathrm{YZ}\right)(\mathrm{a})$ or $\left(\mathrm{B}_{3} \mathrm{XY}\right)(\mathrm{b})$ on $\left(\mathrm{A}_{3} \mathrm{X}_{2}\right)$.

In conclusion, we have shown that the proper combinations of 25 complementary anionic and cationic tectons leads, in the crystalline phase, to the formation of isomorphous and isometric robust and neutral 2-D charge assisted $\mathrm{H}$ bonded networks offering hexagonal-type channels. The crystals are porous and contain water molecules. Taking advantage of 30 their isostructurality, a series of both binary and ternary molecular alloys based on the combination of the same organic tecton with either two or three different complex anions differing by the nature of the central metal have been prepared. Furthermore, the combination of the same anion 35 with two different organic tectons leads to the control of the hydrophilicity/hydrophobicity of the channels and thus the modulation of the temperature of water release. Finally, the hierarchical generation of a series of crystals of crystals or composite crystals by 3-D epitaxial growth processes was 40 demonstrated. This contribution may be considered as a demonstrative example of crystal engineering and offers alternative strategies for the construction of crystalline materials. Work along these lines, in particular the control of other properties in molecular alloys and composite crystals is 45 currently under investigation.

ACKNOWLEDGMENT

Université Louis Pasteur, Institut Universitaire de France, the CNRS and the Ministry of Education and Research are acknowledged for financial support and for a scholarship to P. $50 \mathrm{D}$.

\section{Notes and references}

${ }^{a}$ Laboratoire de Chimie de Coordination Organique, UMR CNRS 7140, Université Louis Pasteur, Institut Le Bel,

4, rue Blaise Pascal, F-67000 Strasbourg, France

${ }_{55} \dagger \quad$ Electronic Supplementary Information (ESI) available: Experimental details for the preparation of molecular alloys and composite crystals, as well as IR characterization and cell parameters for binary and ternary molecular alloys. See DOI: $10.1039 / \mathrm{b} 000000 \mathrm{x} /$

601 A. Name, B. Name and C. Name, Journal Title, 2000, 35, 3523; A. Name, B. Name and C. Name, Journal Title, 2000, 35, 3523.

1 a) J. D.Dunitz, Pure Appl. Chem. 1991, 63, 177.

2 a) S. Mann, Nature, 1993, 365, 499; b) M. Simard, D. Su, J. D. Wuest, J. Am. Chem. Soc., 1991, 113, 4696; c) M. W. Hosseini, Acc. Chem. Res. 2005, 38, 313.

3 )J.-M. Lehn, Supramolecular Chemistry, Concepts and Perspectives, VCH, Weinheim, 1995.

4 a) M.C. Etter, Acc. Chem. Res. 1990, 23, 120; b) M. W. Hosseini, CrystEngComm., 2004, 6, 318.

5 M. W. Hosseini Chem. Commun., 2005, 582.

6 a) D. Braga, G. Cojazzi, D. Paolucci, F. Grepioni, Chem. Commun., 2001, 803; b) S. Ferlay, M. W. Hosseini, Chem. Commun. 2004, 787; c) K. Sada, K. Inoue, T. Tanaka, A. Epergyes, A. Tanaka, N. Tohnai, A. Matsumoto, M. Miyata, Angew. Chem. Int. Ed., 2005, 117, 7221.

7 a) D. L. Dorset, Proc. Natl. Acad. Sci. USA, 1990, 87, 8541; b) M. Maroncelli, H. L. Strauss, R. G. Snyder, J. Phys. Chem. 1985, 89, 5260 ; c) E. B. Sirota, H. E. King, Jr., H. H. Shao, D. M. Singer, J. Phys. Chem. 1995, 99, 798; d) D. Mondieig, P. Espeau, L. Robles, Y. Haget, H. A. J. Oonk, M. A. Cuevas-Diarte, J. Chem. Soc. Faraday Trans. 1997, 93, 3343; e) N. B. Chanh, Y.Bouillard, P. Lencrerot, J. Chim. Phys. 1970, 67, 1206.

8 a) C. B. Aakeröy, K. R. Seddon, Chem. Soc. Rev. 1993, 22, 397; b) S. Subramanian, M. J. Zaworotko, Coord. Chem. Rev. 1994, 137, 357; c) J. C. MacDonald, G. M. Whitesides, Chem. Rev. 1994, 94, 2383; d) G. R. Desiraju, Angew. Chem. Int. Ed. Engl. 1995, 34, 2311.

9 a) A .Russell, M. C. Etter, M. D. Ward, J. Am. Chem. Soc. 1994, 116 1941; b) V. A. Russell, C. C. Evans, W. Li, M. D. Ward, Science, 1997, 276, 575; c) K. T. Holman, A. M. Pivovar, M. D. Ward, Science 2001, 294, 1907; d) M. J. Horner, K. T. Holman, M. D. Ward, J. Am. Chem. Soc. 2007, 129, 14640.

10 M. W. Hosseini, Coord. Chem. Rev. 2003, 240, 157.

11 a) C. J. Kepert, D. Hesek, P. D. Beer, M. J. Rosseinsky, Angew. Chem. Int. Ed., 1998, 37, 3158; b) S. A. Dalrymple, G. K. H. Shimizu, J. Am. Chem. Soc., 2007, 129, 12114.

12 a) L. Brammer, J. K. Swearingen, E. A. Bruton, P. Sherwood, Proc. Natl. Acad. Sci. USA, 2002, 99, 4956; b) G. R. Lewis, A. G. Orpen, Chem. Commun., 1998, 1873; c) A. L. Gillon, A. G. Orpen, J. Starbuck, X-M. Wang, Y. Rodriguez-Martin, C. Ruiz-Pérez, Chem. Commun., 1999, 2287.

13 a) S. Ferlay, O. Félix, M. W. Hosseini, J.-M. Planeix, N. Kyritsakas, Chem. Commun. 2002, 702; b) S. Ferlay, V. Bulach, O. Félix, M. W. Hosseini, J.-M. Planeix, N. Kyritsakas, CrystEngComm 2002, 4, 447; c) S. Ferlay, R. Holakovsky, M. W. Hosseini, J.-M. Planeix, N. Kyritsakas, Chem. Commun. 2003, 1224; d) C. Paraschiv, S. Ferlay, M. W. Hosseini, V. Bulach, J-M. Planeix, Chem. Commun. 2004, 2270; e) P. Dechambenoit, S. Ferlay, M. W. Hosseini, J.-M. Planeix, N. Kyritsakas, New. J. Chem. 2006, 30, 1403; f) P. Dechambenoit, S. Ferlay, M. W. Hosseini, N. Kyritsakas N. Chem. Commun. 2007, 4626.

14 P. Dechambenoit, S. Ferlay, M. W. Hosseini, N. Kyritsakas N. J. Am. Chem. Soc., 2008, DOI: 10.1021/ja806916t.

15 L. Vegard, Z. Kristallogr., 1928, 67, 239.

16 a) J. C. MacDonald, P. C. Dorrestein, M. M. Pilley, M. M. Foote, J. L. Lundburg, R. W. Henning, A. J. Schultz, J. L. Manson, J. Am. Chem. Soc. 2000, 122, 11692; (b) J. C. Noveron, M. S. Lah, R. E. Del Sesto, A. M. Arif, J. S. Miller, P. J. Stang J. Am. Chem. Soc. $2002, \mathbf{1 2 4}, 6613$ 
17 a) J. D. Wright Molecular Crystals; Cambridge University Press: New York, 1995; b) R. D. Bailey, L. L. Hook, A. K. Powers, T. W. Hanks, W. T. Pennington, Cryst. Eng. 1998, 1, 51; c) C. A. Mitchell, L. Yu, M. D. Ward J. Am. Chem. Soc. 2001, 123, 10830; d) J. Fraxedas Adv. Mater. 2002, 14, 1603.

18 a) P. Dechambenoit, S. Ferlay, M. W. Hosseini Cryst. Gr. Des. 2005, 5, 2310; b) E. F. Brès, S. Ferlay, P. Dechambenoit, H. Leroux, M. W. Hosseini, S. Reyntjens J. Mater. Chem. 2007, 1559. 